\title{
Understanding the Importance of Dopaminergic Deficit in Reward Deficiency Syndrome (RDS): Redeeming Joy Overcoming "Darkness" in Recovery
}

\author{
Kenneth Blum ${ }^{1,2,3,4,5,6,7,8,9,10^{*}}$, Mary Hauser7, Gozde Agan7, John Giordano11, \\ James Fratantonio ${ }^{7}$, Rajendra D. Badgaiyan'11, Marcelo Febo1 \\ ${ }^{1}$ Department of Psychiatry \& Mcknight Brain Institute, University of Florida College of Medicine, Gainesville, FL, \\ USA \\ ${ }^{2}$ Human Integrated Services Unit University of Vermont Center for Clinical \& Translational Science, College of \\ Medicine, Burlington, VT, USA \\ ${ }^{3}$ Department of Nutrigenomics, RD Solutions, Salt Lake City, Utah, USA \\ ${ }^{4}$ Victory Nutrition International, LLC, Lederoch, Penn, USA \\ ${ }^{5}$ Department of Clinical Neurology, Path Foundation, New York, NY, USA \\ ${ }^{6}$ Department of Personalized Medicine, IGENE, LLC, Austin, Texas, USA \\ ${ }^{7}$ Dominion Diagnostics, LLC, North Kingstown, Rhode Island, USA \\ ${ }^{8}$ Department of Addiction Research \& Therapy, Malibu Beach Recovery Center, Malibu Beach, California, USA \\ ${ }^{9}$ Department of Clinical Research, Nupathways, Inc., Indianapolis, Indiana, USA \\ ${ }^{10}$ Department of Holistic Medicine, National Institute of Holistic Studies, North Miami Beach, Florida, USA \\ ${ }^{11}$ Department of Psychiatry, University of Minnesota College of Medicine, Minneapolis, USA \\ Email: ${ }^{*}$ drd2gene@gmail.com
}

Received 26 February 2015; accepted 12 March 2015; published 16 March 2015

Copyright @ 2015 by authors and Scientific Research Publishing Inc.

This work is licensed under the Creative Commons Attribution International License (CC BY).

http://creativecommons.org/licenses/by/4.0/

c) (i) Open Access

\begin{abstract}
Dopamine's role is central to motivation, pleasure states and anti-stress behavioral traits. Throughout five decades of observations of prevention, diagnosis, and tertiary treatment, many positive changes have been instrumental in the enhancement of lives of millions. However, we have not yet developed any workable "Standard of Care" for the chronic disorder known as "Reward Deficiency Syndrome (RDS)" first coined by Blum's laboratory in 1996. In the 1980s, the addiction field turned toward adoption of the well-known 12-step program to assist in the treatment for many addictions. The biological psychiatry field together with the pharmaceutical industry developed an array of "Medication Assisted Treatment (MAT)" compounds approved for alcohol

\footnotetext{
${ }^{*}$ Corresponding author.
}

How to cite this paper: Blum, K., Hauser, M., Agan, G., Giordano, J., Fratantonio, J., Badgaiyan, R. D., \& Febo, M. (2015). Understanding the Importance of Dopaminergic Deficit in Reward Deficiency Syndrome (RDS): Redeeming Joy Overcoming "Darkness" in Recovery. Psychology, 6, 435-439. http://dx.doi.org/10.4236/psych.2015.64040 
and opioids but not psychostimulants. Furthermore, the FDA approved drugs favoring the blocking of dopamine instead of its important activation based on deficit especially in terms of blunted reward response at the pre-frontal cortices and meso limbic brain regions. A major problem is that powerful dopamine D2 agonists chronically induce down-regulation of dopaminergic function leaving a gap between dopamine agonistic therapy (up-regulation over a long period of time) and promotion of dopamine homeostatic mechanisms. This editorial will focus on the incorporation of appropriate diagnosis of genetic risk utilizing a novel panel of genes (SNPs), advanced urine drug testing "Comprehensive Analysis of Reported Drugs (CARD)" and enhancement of functional connectivity with a complex putative dopaminergic D2 agonist KB220Z. Until we can incorporate these and other holistic approaches, the relapse rate will continue to be unacceptable. It is important to re-evaluate our current treatment tactics including dopaminergic activation in the longterm as part of the after-care program in the 14,500 treatments center in the United States alone. In doing so, we may be able to overcome this horrific societal dilemma redeeming "dopamine Joy" in recovery bringing light to the reward system instead of darkness.

\section{Keywords}

Reward Deficiency Syndrome, Dopamine, Genetic Addiction Risk Score, Comprehensive Analysis of Reported Drugs (CARD), Dopamine Agonist Modalities (DAM)

\section{Introduction}

Over the last 50 years of a journey in the exciting field of “Addiction Medicine”, one of us (KB) has seen remarkable change in our scientific understanding of how psychoactive drugs influence behavior through a very complex action on neuronal pathways especially in the mesolimbic system and the Prefrontal Cortex-Cingulate gyrus of the brain (Bowirrat et al., 2012). During this period, we have had the distinct pleasure of not only working with some of the giants in the field but personally interacting with many of them (Blum, 1991). While the concept of recovery became a household word incorporating the 12-step program \& fellowship, it is our belief that introducing a new definition of “addiction” espoused by the American Society of Addiction Medicine (ASAM) will have tremendous impact on our younger generations to come accepting the well-established phenomena that addiction is indeed a brain disorder (Smith, 2012).

Blum's work with Ernest P. Noble and their esteemed associates in discovering the first gene to associate with severe alcoholism (Blum et al., 1990) that sparked the current field of Psychiatric Genetics, is certainly a landmark event. We are now poised in the $21^{\text {st }}$ century through the era of genomic medicine to begin to understand the true nature of this brain disorder that Blum intuitively coined "Reward Deficiency Syndrome (RDS) (Blum, Braverman, Kreuk et al., 2014).

\section{Mechanisms of Addiction}

Reflecting over these many years there are a number of important examples of progress: understanding of the neurochemical mechanisms involved in the addiction process including withdrawal symptomatology (Zandy et al., 2014); understanding the physiological basis for brain neurotransmission (Williams et al., 2014); understanding neurochemical mechanisms for synaptic function (Talani et al., 2014); understanding the role of longterm potentiation in drug self-administration and sensitization (Polter et al., 2014); understanding the neurobiological mechanisms of storage, release and catabolism of neurotransmitters in pre and post synaptic loci (Palm \& Nylander, 2014); understanding the role of the "Brain Reward Cascade" in craving behavior and relapse (Chen et al., 2012); and understanding the role of neurogenetics and epigenetics in all aspects of drug seeking and process addictions (Starkman, Sakharkar, \& Pandey, 2012). One in particular argues that childhood maltreatment alters brain grey matter which may induce relapse to psychoactive drugs later in life (Van Dam et al., 2014).

\section{Super Controls}

However, with all of this positive and remarkable understanding we have a long way to go before we can say 
that science has caught up with this very complex brain disorder known as RDS. A priori have we been looking at the genetics in simplistic fashion (candidate gene approaches) compared to GWAS evaluation of a large body of genes (clusters)? Should we pay more attention to epigenetic effects and continue our pursuit through EWAS studies? In regard to this rhetoric we submit to our scientific partners that it seems reasonable that based on wellknown physiological mechanisms that we should not "toss the baby out with the bathwater" (Blum, Han, Femino et al., 2014).

In our point of view in spite of a number of GWAS studies having difficulty in finding significantly large associations with various gene candidates (small associations ) may be due to a number of factors such the complex nature of the disorder being polygenic and most importantly the flawed utilization of seemingly reasonable controls (Van Dam et al., 2014). If indeed our associates and us are correct about the true phenotype of "addiction” which constitutes RDS and all of its subtypes (e.g. drugs, alcohol, nicotine, food, sex etc.) then it make's good scientific sense to rigorously screen controls for these RDS subtypes prior to systematic analysis whether one prefers the candidate or GWAS approach (Blum, Oscar-Berman, Demetrovics et al., 2014).

In fact progress is already on its way (Chen et al., 2005). However, unfortunately having the disease as part of the controls will only lead to spurious and useless results. While this question will take years to dissect we would, like to turn our attention to the clinical management of the RDS patient. It is well known that patients (especially when young) that present to a treatment center by force (court, family and friends intervention) will deny the real ongoing brain related issue (Morrison, 1990).

\section{Genetic Testing and Medical Monitoring}

While there may be a number of reasons including denial to develop a non-invasive genetic test for RDS based on known allelic associations such as the proposed "Genetic Addiction Risk Score (GARSDX) "that will allow for stratification of genetic risk in an individual, should at the very least provide a "mirror to the brain" thereby reducing some guessing in terms of brain function (Blum et al., 2013). Obviously there are other clinical benefits such as medical monitoring (Crist et al., 2013) for pharmacogenetic response of a drug (Anton et al., 2008); metabolic issues of drug delivery (Bahi \& Dreyer, 2008); tailored customized medical necessity for type of clinical care (Levey et al., 2014); pharmacogenomic treatment targeting gene polymorphisms (Blum et al., 2006); and a host of other clinical benefits including family curiosity and wiliness to participate in the patient's recovery plan. The genetic test should be coupled with methodology involving urine drug testing (Comprehensive Analysis of Reported Drugs (CARD) (Blum, Han, Femino et al., 2014) evaluating both compliance to FDA approved treatment medications and abstinence from licit and illicit.

\section{Dopamine Agonist Modalities (DAM)}

For many years cocaine escalation was considered to occur when dopamine increases in the reward circuitry of the brain. In fact this was the basis for all psychoactive drugs of abuse because they all induce neuronal dopamine release. This conceptual framework has resulted in blocking dopaminergic function in the brain as seen in the current list of FDA approved drugs for both alcohol and opioid dependence. However, the concept of dopamine surfeit compared to deficit theories has been argued in favor of deficit for the known escalation of for example cocaine (Willuhn et al., 2014). As such this newer imaging work favors dopamine agonist modalities (DAM) rather than dopamine antagonist therapy for all RDS behaviors. It is also important to embrace the surfeit theory of stress which also reduces reward circuitry dopamine (Wise \& Koob, 2014).

\section{Conclusion}

In summary, we must ask the question "when will science meet recovery?" The answer is unknown but we are making great strides in this direction and through appropriate dissemination of both basic science and clinical science especially on recovery (including neuroimaging and genetic research and molecular biological explanations of the 12 steps). We will someday prevail and learn how to reintroduce "Dopamine Joy" in the now billions worldwide linked to unwanted addictive behaviors due to dopamine deficit. The key is to "lick your pups" and start early intervention especially in those found to carry DNA polymorphic risk.

\section{Author Contribution}

All authors contributed equally. 


\section{Acknowledgements}

The authors appreciate the editorial assistance of Margaret A. Madigan. Marcelo Febo is the recipient of R01DA019946. Rajendra D. Badgaiyan is supported by the National Institutes of Health grants 1R01NS073884 and 1R21MH073624; and VA Merit Review Awards CX000479 and CX000780.

\section{Conflict of Interests}

Kenneth Blum holds US and foreign patents pending on genetic testing and nutrigenomics. Mary Houser, James Fratantonio and Gozde Agan are employed by Dominion Diagnostics, LLC. Dr. Blum is a paid consultant of Dominion Diagnostics LLC. Dr. Blum owns stock in RD Solutions, Inc., Victory Nutrition International, LLC, Igene LLC and Synaptamine, Inc. He is a paid consultant of Path Foundation NY and Malibu Beach Recovery Center. There are no other conflicts to report from the current authors.

\section{References}

Anton, R. F., Oroszi, G., O’Malley, S., Couper, D., Swift, R., Pettinati, H., \& Goldman, D. (2008). An Evaluation of muOpioid Receptor (OPRM1) as a Predictor of Naltrexone Response in the Treatment of Alcohol Dependence: Results from the Combined Pharmacotherapies and Behavioral Interventions for Alcohol Dependence (COMBINE) Study. Archives of General Psychiatry, 65, 135-44. http://dx.doi.org/10.1001/archpsyc.65.2.135

Bahi, A., \& Dreyer, J. L. (2008). Overexpression of Plasminogen Activators in the Nucleus Accumbens Enhances Cocaine-, Amphetamine- and Morphine-Induced Reward and Behavioral Sensitization. Genes, Brain and Behavior, 7, $244-256$. http://dx.doi.org/10.1111/j.1601-183X.2007.00346.x

Blum, K. (1991). Alcohol and the Addictive Brain. New York: The Free Press.

Blum, K., Braverman, E. R., Kreuk, F., Dushaj, K., Li, M. et al. (2014). Genome Wide Sequencing Compared to Candidate Gene Association Studies for Predisposition to Substance Abuse a Subset of Reward Deficiency Syndrome (RDS): Are We Throwing the Baby out with the Bathwater? Epidemiology, 4, 158. http://dx.doi.org/10.4172/2161-1165.1000158

Blum, K., Chen, T. J., Meshkin, B., Downs, B. W., Gordon, C. A., Blum, S., Mengucci, J. F., Braverman, E. R., Arcuri, V., Varshavskiy, M., Deutsch, R., \& Martinez-Pons, M. (2006). Reward Deficiency Syndrome in Obesity: A Preliminary Cross-Sectional Trial with a Genotrim Variant. Advances in Therapy, 23, 1040-1051. http://dx.doi.org/10.1007/BF02850224

Blum, K., Han, D., Femino, J., Smith, D. E., Saunders, S., Simpatico, T., Schoenthaler, S. J., Oscar-Berman, M., \& Gold, M. S. (2014). Systematic Evaluation of “Compliance” to Prescribed Treatment Medications and "Abstinence” from Psychoactive Drug Abuse in Chemical Dependence Programs: Data from the Comprehensive Analysis of Reported Drugs. PlosOne, 9, e104275. http://dx.doi.org/10.1371/journal.pone.0104275

Blum, K., Noble, E. P., Sheridan, P. J., Montgomery, A., Ritchie, T., Jagadeeswaran, P., Nogami, H., Briggs, A. H., \& Cohn, J. B. (1990). Allelic Association of Human Dopamine D2 Receptor Gene in Alcoholism. JAMA, 263, 2055-2060. http://dx.doi.org/10.1001/jama.1990.03440150063027

Blum, K., Oscar-Berman, M., Demetrovics, Z., Barh, D., \& Gold, M.S. (2014). Genetic Addiction Risk Score (GARS): Molecular Neurogenetic Evidence for Predisposition to Reward Deficiency Syndrome (RDS). Molecular Neurobiology, 50, 765-796.

Blum, K., Oscar-Berman, M., Dinubile, N., Giordano, J., Braverman, E. R., Truesdell, C. E., Barh, D., \& Badgaiyan, R. D. (2013). Coupling Genetic Addiction Risk Score (GARS) with Electrotherapy: Fighting Iatrogenic Opioid Dependence. Journal of Addiction Research Therapy, 4, Article ID: 1000163.

Bowirrat, A., Chen, T. J., Oscar-Berman, M., Madigan, M., Chen, A. L., Bailey, J. A., Braverman, E. R., Kerner, M., Giordano, J., Morse, S., Downs, B. W., Waite, R. L., Fornari, F., Armaly, Z., \& Blum, K. (2012). Neuropsychopharmacology and Neurogenetic Aspects of Executive Functioning: Should Reward Gene Polymorphisms Constitute a Diagnostic Tool to Identify Individuals at Risk for Impaired Judgment? Molecular Neurobiology, 45, 298-313.

http://dx.doi.org/10.1007/s12035-012-8247-z

Chen, K. C., Lin, Y. C., Chao, W. C., Chung, H. K., Chi, S. S., Liu, W. S., \& Wu, W. T. (2012). Association of Genetic Polymorphisms of Glutamate Decarboxylase 2 and the Dopamine D2 Receptor with Obesity in Taiwanese Subjects. Annals of Saudi Medicine, 32, 121-126.

Chen, T. J., Blum, K., Mathews, D., Fisher, L., Schnautz, N., Braverman, E. R., Schoolfield, J., Downs, B. W., \& Comings, D. E. (2005). Are Dopaminergic Genes Involved in a Predisposition to Pathological Aggression? Hypothesizing the Importance of "Super Normal Controls" in Psychiatricgenetic Research of Complex Behavioral Disorders. Medical Hypotheses, 65, 703-707. http://dx.doi.org/10.1016/j.mehy.2005.04.037 
Crist, R. C., Clarke, T. K., Ang, A., Ambrose-Lanci, L. M., Lohoff, F. W., Saxon, A. J., Ling, W., Hillhouse, M. P., Bruce, R. D., Woody, G., \& Berrettini, W. H. (2013). An Intronic Variant in OPRD1 Predicts Treatment Outcome for Opioid Dependence in African-Americans. Neuropsychopharmacology, 38, 2003-2010. http://dx.doi.org/10.1038/npp.2013.99

Levey, D. F., Le-Niculescu, H., Frank, J., Ayalew, M., Jain, N., Kirlin, B., Learman, R., Winiger, E., Rodd, Z., Shekhar, A., Schork, N., Kiefe, F., Wodarz, N., Müller-Myhsok, B., Dahmen, N., GESGA Consortium, Nöthen, M., Sherva, R., Farrer, L., Smith, A. H., Kranzler, H. R., Rietschel, M., Gelernter, J., \& Niculescu, A. B. (2014). Genetic Risk Prediction and Neurobiological Understanding of Alcoholism. Translational Psychiatry, 4, e391. http://dx.doi.org/10.1038/tp.2014.29

Palm, S., \& Nylander, I. (2014). Dopamine Release Dynamics Change during Adolescence and after Voluntary Alcohol Intake. PLOS One, 9, e96337. http://dx.doi.org/10.1371/journal.pone.0096337

Polter, A. M., Bishop, R. A., Briand, L. A., Graziane, N. M., Pierce, R. C., \& Kauer, J. A. (2014). Poststress Block of Kappa Opioid Receptors Rescues Long-Term Potentiation of Inhibitory Synapses and Prevents Reinstatement of Cocaine Seeking. Biological Psychiatry, 76, 785-793.

Morrison, M. A. (1990). Addiction in Adolescents. Western Journal of Medicine, 152, 543-546.

Smith, D. E. (2012). The Process Addictions and the New ASAM Definition of Addiction. Journal of Psychoactive Drugs, 44, 1-4. http://dx.doi.org/10.1080/02791072.2012.662105

Starkman, B. G., Sakharkar, A. J., \& Pandey, S. C. (2012). Epigenetics-Beyond the Genome in Alcoholism. Alcohol Research, 34, 293-305.

Talani, G., Licheri, V., Masala, N., Follesa, P., Mostallino, M. C., Biggio, G., \& Sanna, E. (2014). Increased Voluntary Ethanol Consumption and Changes in Hippocampal Synaptic Plasticity in Isolated C57BL/6J Mice. Neurochemical Research, 39, 997-1004. http://dx.doi.org/10.1007/s11064-013-1216-8

Van Dam, N. T., Rando, K., Potenza, M. N., Tuit, K., \& Sinha, R. (2014). Childhood Maltreatment, Altered Limbic Neurobiology, and Substance Use Relapse Severity via Trauma-Specific Reductions in Limbic Gray Matter Volume. JAMA Psychiatry, 71, 917-925.

Williams, C. L., Buchta, W. C., \& Riegel, A. C. (2014). CRF-R2 and the Heterosynaptic Regulation of VTA Glutamate during Reinstatement of Cocaine Seeking. Journal of Neuroscience, 34, 10402-10414.

http://dx.doi.org/10.1523/JNEUROSCI.0911-13.2014

Willuhn, I., Tose, A., Wanat, M. J., Hart, A. S., Hollon, N. G., Phillips, P. E., Schwarting, R. K., \& Wöhr, M. (2014). Phasic Dopamine Release in the Nucleus Accumbens in Response to Pro-Social $50 \mathrm{kHz}$ Ultrasonic Vocalizations in Rats. Journal of Neuroscience, 34, 10616-10623. http://dx.doi.org/10.1523/JNEUROSCI.1060-14.2014

Wise, R. A., \& Koob, G. F. (2014). The Development and Maintenance of Drug Addiction. Neuropsychopharmacology, 39, 254-262. http://dx.doi.org/10.1038/npp.2013.261

Zandy, S. L., Matthews, D. B., Tokunaga, S., Miller, A. D., Blaha, C. D., \& Mittleman, G. (2014). Reduced Dopamine Release in the Nucleus Accumbens Core of Adult Rats Following Adolescent Binge Alcohol Exposure: Age and Dose-Dependent Analysis. Psychopharmacology, 232, 777-784. 